\title{
LA OSCILANTE DOCTRINA DEL TRIBUNAL CONSTITUCIONAL SOBRE LA DEFINICIÓN DE LAS CONSULTAS POPULARES POR LA VÍA DE REFERÉNDUM. UNA REVISIÓN CRÍTICA A TRAVÉS DE CUATRO SENTENCIAS ${ }^{1}$
}

\author{
Joan Ridao Martín
}

\begin{abstract}
SUMARIO: 1. INTRODUCCIÓN: EL PLANTEAMIENTO CONSTITUCIONAL DE LAS CONSULTAS POPULARES DESPUÉS DE LA STC 31/2015. 2. LA DELIMITACIÓN DEL GÉNERO CONSULTAS POPULARES EN LA JURISPRUDENCIA DEL TRIBUnAl CONSTITUCIONAL. LA REFERENCIA DE LA STC 103/2008. 2.1. El género de la consulta popular como confluencia de derechos constitucionales. 2.2. La definición de la consulta referendaria en la jurisprudencia y la doctrina. 2.3. La definición de la consulta popular no referendaria por exclusión: el ejemplo de la Ley del Parlamento de Catalunya 10/2014. 3. LAS COMPETENCIAS DE LA GENERALITAT EN MATERIA DE CONSULTAS POPULARES. 3.1. Las consultas populares en el Estatuto de 2006 y su desarrollo. El efecto de la STC 31/2010. 3.2. La matización de las restricciones a la capacidad autonómica en la STC 42/2014. 4. LAS MATERIAS SUSCEPTIBLES DE SER OBJETO DE CONSULTA: JURISPRUDENCIA Y DOCTRINA. 5. CONCLUSIONES.
\end{abstract}

${ }^{1}$ Este trabajo ha sido realizado en el marco del Proyecto «La reforma constitucional del estado autonómico en la perspectiva del federalismo del siglo XXI», financiado por el Ministerio de Ciencia e Innovación (Código: DER2011-28600), del que es investigador principal el Dr. Juan Vintró i Castells, de la Universidad de Barcelona. 


\section{INTRODUCCIÓN: EL PLANTEAMIENTO CONSTITUCIONAL DE LAS CONSULTAS POPULARES DESPUÉS DE LA STC 31/2015}

Con la emisión por parte del Tribunal Constitucional (TC) de su sentencia (STC) $31 / 2015$, de 25 de febrero $^{2}$, por la que declara inconstitucional la figura de la consulta popular general regulada en la Ley del Parlamento de Catalunya 10/2014, el Alto Tribunal ha concluido, en lo substancial ${ }^{3}$, un proceso de destilación doctrinal entorno a la institución del referéndum y por añadidura del género de las consultas populares. Dicho proceso se ha vehiculado, además de en la sentencia mencionada, a través de otras tres conocidas sentencias anteriores (las SSTC 103/2008, 31/2010 y 42/2014), que han venido a desplegar un amplio cuerpo jurisprudencial sobre el alcance, contenido y competencias relativas al uso de ambos conceptos, que compensa, en parte, la esquemática referencia que hace el Texto constitucional, y el extraordinariamente sucinto desarrollo legislativo que fue objeto el instituto referendario en la Ley Orgánica 2/1980, de 18 de enero, Reguladora de las distintas modalidades de referéndum (LORMR).

${ }^{2}$ De forma conexa, el TC emitió, en la misma fecha, la STC 32/2015 por la que declaró inconstitucionales y nulos el Decreto del Presidente de la Generalitat de Cataluña 129/2014, de 27 de septiembre, de convocatoria de la consulta popular no referendaria sobre el futuro político de Cataluña y sus anexos. Los fundamentos de esta Sentencia, sin embargo, se limitan a aplicar los expresados en la precedente $31 / 2015$, al caso concreto de la consulta regulada en el mencionado Decreto, sin que haya aportación significativa de nueva jurisprudencia.

3 Por lo que se refiere al denominado «proceso catalán», en el momento de redactar este artículo queda por dilucidar el recurso interpuesto por el gobierno del Estado contra la Ley catalana 4/2010, de consultas por vía de referéndum, respecto de la cual no parece que pueda recaer un pronunciamiento que se separe del criterio manifestado en la relevante STC 31/2010, de 28 de junio, sobre el Estatuto de autonomía de Cataluña (Fundamento Jurídico [FJ] 69) (Vid. VINTRÓ CASTELLS, J., «El Tribunal Constitucional y la consulta en Cataluña: certezas, ambigüedades, decepción», Eldiario.es, 28.02.2015. Disponible: $<$ http://www.eldiario.es/agendapublica/reforma-constitucional/Trubunal-Constitucional-Cataluna-ambiguedades-decepcion_0_361514308.html $>$ [Consultado el 20.04.2015]); también cabe señalar que el Gobierno del Estado interpuso recurso contra distintas «actuaciones de la Generalitat de Cataluña relativas a la convocatoria a las personas residentes en Cataluña para que manifiesten su opinión sobre el futuro político de Cataluña el día 9 de noviembre de 2014 y siguientes, mediante el denominado "proceso de participación ciudadana" (asunto 6540-2014)», de más incierta resolución. Más allá, pueden ser relevantes los pronunciamientos que el Alto Tribunal debe realizar sobre las impugnaciones, también del Gobierno, contra los Decretos del Gobierno de Canarias 95/2014, de 25 de septiembre, por el que se aprueba el Reglamento de las consultas a la ciudadanía en asuntos de interés general de competencia de la Comunidad Autónoma; y 107/2014, de 2 de octubre, del Presidente del Gobierno de Canarias, por el que se convoca consulta ciudadana mediante pregunta directa en aplicación del anterior decreto (asuntos 6415-2014 y 6416-2014, respectivamente). 
No puede obviarse el hecho, además, de que este acervo de recientes pronunciamientos del TC han tenido como destinatarios los poderes políticos de dos Comunidades Autónomas, Cataluña y el País Vasco, que han expresado, en distintos momentos y por distintas vías, el objetivo de establecer los cauces para ejercer el llamado «derecho a decidir», entendiendo por tal la realización de una consulta al conjunto de la ciudadanía de los respectivos territorios, mediante un procedimiento y unas garantías equivalentes a las de una convocatoria electoral, relativa a un eventual cambio en la naturaleza política de la vinculación entre aquellos y el Estado español, sin anteceder necesariamente a dicha consulta un proceso formal de reforma constitucional. Esto es, junto a la controversia doctrinal subyace un debate de poderosa transcendencia política, en el que entran en juego conceptos troncales del sistema constitucional como el principio democrático, la soberanía o la integridad territorial del Estado.

Como se recordará, la STC 103/2008, tenía como origen la Ley Vasca 9/2008, de 27 de junio, de convocatoria y regulación de una consulta popular al objeto de recabar la opinión ciudadana en la Comunidad Autónoma del País Vasco sobre la apertura de un proceso de negociación para alcanzar la paz y la normalización política ${ }^{4}$. Por su parte, el la STC 31/2010 (FJ 69) atendía directamente a la atribución de la competencia exclusiva, a favor de la Generalitat de Cataluña, en materia de consultas populares no referendarias, ex artículo 122 del Estatuto de Autonomía de Cataluña de 2006 (EAC), mientras que las otras dos sentencias restantes se hallan vinculadas a sendas iniciativas adoptadas en el marco del «proceso catalán» para el ejercicio del «derecho a decidir», iniciado tras las elecciones autonómicas de noviembre de 2012.

En cualquier caso, la tesis que desarrolla este trabajo es la de que, del conjunto de la jurisprudencia constitucional a que hemos hecho referencia, se desprende un criterio de progresiva restricción, por un lado, en cuanto al uso y competencias para la regulación y convocatoria de las consultas populares, que vacía de contenido las competencias asumidas en este ámbito por algunas Comunidades Autónomas en el marco de los llamados «estatutos de nueva generación $»^{5}$; pero también por lo que respecta a las materias que

${ }^{4}$ Para una exposición detallada del contenido y contexto de la Ley vasca 9/2008, vid. RIDAo MARTín, J., «La poderosa y alargada sombra de la STC 103/2008 sobre la Ley vasca de consulta en el ejercicio del "derecho a decidir" un nuevo marco político para Catalunya», Revista Vasca de Administración Pública, núm. 99-100, mayo-diciembre, 2014, pp. 2543-2575.

5 Al caso catalán, cabe añadir los de Andalucía (LO 2/2007, de 19 de marzo, art. 78) y Aragón (LO 5/2007, de 20 de abril, art. 71.27). Aunque la conflictividad constitucional giró en torno al EAC, el resto de Estatutos similares no puede permanecer, lógicamente, ajeno a esta jurisprudencia. 
pueden ser objeto de consulta mediante el instituto referendario. Y, todo ello, teniendo en cuenta, además, que la justificación doctrinal expuesta por el Alto Tribunal adolece de un sesgo, sino errático, sí ciertamente dubitativo y algo confuso, lo que le ha valido no pocas críticas desde orientaciones doctrinales diametralmente opuestas entre sí.

Para la exposición de dicho enunciado, en el presente trabajo se analizan, en primer lugar, la delimitación del género consultas populares, con referencias específicas a las modalidades referendaria y no referendaria en la jurisprudencia asentada por las cuatro sentencias objeto de nuestro escrutinio; en segundo lugar, se examina la situación de las competencias autonómicas en el ámbito de las consultas populares tras los referidos pronunciamientos; para, finalmente, discutir los criterios que dimanan de la mencionada doctrina constitucional respecto a la limitación en las materias que pueden ser objeto de consulta.

\section{LA DELIMITACIÓN DEL GÉNERO CONSULTAS POPULARES EN LA JURISPRUDENCIA DEL TRIBUNAL CONSTITUCIONAL. LA REFERENCIA DE LA STC 103/2008}

\subsection{El género de la consulta popular como confluencia de derechos constitucionales}

Como es sobradamente conocido, a partir de la interpretación sistemática que estableció ${ }^{6}$ la STC 103/2008 (FJ 2), la jurisprudencia remite a una relación género/especie entre consultas populares y referéndums. Esta interpretación se enmarca, además, en una Norma Fundamental que establece una democracia dotada de una pluralidad de instrumentos participativos de los ciudadanos en la vida pública y en el destino colectivo, ya sea mediante el ejercicio del derecho de participación política ex artículo 23.1 CE, esto es, a través de las elecciones periódicas de representantes en las Cortes Generales (arts. 68 y $69 \mathrm{CE}$ ), en los Parlamentos autonómicos (art. 152.1 CE) y en los Ayuntamientos (art. $140 \mathrm{CE}$ ); ya sea por medio de la participación directa de los ciudadanos en los asuntos públicos, como cauce de conformación y expresión de la voluntad general, en relación al destino político de la comunidad en todas sus esferas (estatal, autonómica y local); o incluso, a otro nivel, como manifestación del «fenómeno participativo», cuya promoción se enco-

${ }^{6}$ El núcleo argumental, sin embargo, es tributario de anteriores sentencias del Alto Tribunal (por todas, vid. SSTC 63/1987 FJ5, 49/1994 FJ 3 y 119/1995 FJ 3), que basan la taxonomía en la textual referencia a las «consultas populares por vía de referéndum» (art 149.1.32 $\mathrm{CE})$. 
mienda, con carácter general, a los poderes públicos en relación a los ámbitos político, económico, cultural y social (art. 9.2 CE) ${ }^{7}$.

Aunque, evidentemente, la primera inferencia que cabe extraer de la relación género/especie a que hemos aludido, es la implícita admisión de la existencia de consultas populares no referendarias ${ }^{8}$, lo cierto es que la jurisprudencia del TC, hasta la STC 31/2015, apenas ofrecía elementos que permitiesen definir sus contornos con nitidez ni siquiera la aproximación a una configuración de sus contenidos. De modo que, en contraste con la exhaustividad del tratamiento del instituto referendario, esta otra especie de las consultas populares gozaba de un carácter subsidiario, delimitado por exclusión. Tanto es así que, dado el carácter eminentemente orgánico-procedimental, como más adelante desarrollaremos, de la configuración establecida por la jurisprudencia constitucional sobre la naturaleza del instituto referendario, para el legislador estatutario parecía abrirse, en una primera lectura, la posibilidad de configurar contrario sensu, y dentro de las consultas populares no referendarias, un instrumento de democracia participativa de nueva planta,

${ }^{7}$ Así, tras establecerse con carácter general que los poderes públicos facilitarán «la participación de todos los ciudadanos en la vida política, económica, cultural y social» (art. 9.2), se perfilan dichas formas participativas en el terreno político: a través de los partidos políticos (art. 6), directamente o por medio de representantes en los asuntos públicos (art. 23.1), en la iniciativa legislativa (art. 87.3), en el procedimiento de elaboración de disposiciones que les afecten (art. 105.a), y en la Administración de justicia mediante el jurado (art. 125); en la esfera económica: a través de las asociaciones de consumidores (art. 51), de los trabajadores en la empresa (art. 129.2), y de los sindicatos, organizaciones profesionales, empresariales y económicas en la planificación (art. 131.2); y en la vida cultural y social: por medio de la intervención en la programación general de la enseñanza de todos los sectores afectados (art. 27.5), de la juventud en el desarrollo político, social, económico y cultural (art. 48), y de los interesados en la Seguridad Social y en la actividad de los organismos públicos cuya función afecte a la calidad de vida o bienestar general (art. 129.1). Finalmente la Constitución garantiza «la convivencia democrática» y el establecimiento de «una sociedad democrática avanzada» (Preámbulo), para lo que prescribe la estructura y funcionamiento democrático de: los partidos políticos (art. 6), los sindicatos de trabajadores y asociaciones empresariales (art. 7), de los Colegios profesionales (art. 36) y de las organizaciones profesionales para la defensa de intereses económicos (art. 52).

${ }^{8}$ En este sentido, la STC 31/2015 (FJ 5) subraya que «[1]a Constitución, al referirse en el art. 149.1.32 a las "consultas populares por vía de referéndum" ha consentido la existencia de otras consultas populares que no fueran las referendarias, habiendo sido el legislador orgánico y estatutario el que las ha introducido en el bloque de constitucionalidad (en lo que aquí interesa, el art. 122 EAC, al conferir a la Generalitat competencia en materia de "encuestas, audiencias públicas, foros de participación y cualquier otro instrumento de consulta popular"). Por tanto, bajo aquella denominación genérica debe comprenderse la existencia de dos instituciones de raíz diferente: el referéndum y las consultas no referendarias». 
capaz de pulsar, con una representatividad contrastable, el parecer del conjunto de la ciudadanía sobre determinadas decisiones políticas, exento de la tutela estatal que la CE establece para el referéndum ex art. 149.1.32 ${ }^{\mathrm{a} 9}$. Como veremos, esta posibilidad ha quedado definitivamente cercenada con el giro doctrinal de la STC 31/2015.

Además, concurría la nada desdeñable circunstancia de que las consultas populares de ámbito autonómico, con excepción de los supuestos referendarios contemplados expresamente en la $\mathrm{CE}$, a los que también hemos de referirnos después, no aparecían contempladas en ninguna norma estatal. Lo cual, por lo demás, contrastaba con el tratamiento que habían recibido las consultas en el nivel local, que, en el ámbito estatal, habían meritado un reconocimiento expreso (disposición adicional LORMR y art. 71 de la 7/1985, de 2 de abril, reguladora de las bases del régimen local [LRBRL]), diferenciadas de la especie referendaria y sometidas a la autorización previa estatal, si bien algunos desarrollos autonómicos (Ley 5/1997, de 22 de julio, de la Administración Local de Galicia y Ley 2/2001, de 3 de mayo, reguladora de las consultas populares locales) las dotaron de garantías que la STC 103/2008 consideró privativas del referéndum, sin que ello, por cierto, haya generado conflictividad constitucional alguna.

Por otro lado, en la STC 103/2008, como antes había hecho en las SSTC 76/1994 (FJ 3) y 119/1995 (FJ 3), el TC destacó la importancia de los instru-

${ }^{9}$ Esta ventana no sólo ha sido utilizada en el caso de Cataluña, como ejemplo emblemático de los «estatutos de nueva generación» con competencias en materia de consultas populares, sino también, por ejemplo, por la Comunidad Autónoma de Canarias, que aprobó un Reglamento de las consultas a la ciudadanía en asuntos de interés general de su competencia (Decreto 95/2014, de 25 de septiembre) al amparo de la Ley canaria de 5/2010, de 21 de junio, de Fomento a la Participación Ciudadana y en el marco del Estatuto de Autonomía de 1982. En dicho Reglamento se establece (arts. 9 y siguientes) la consulta popular mediante la modalidad de las «preguntas directas», la cual «será decidida por el Gobierno y estará dirigida a recabar la opinión, en función de la actuación o política pública a la que se refiera, en el ámbito de sus competencias, de las entidades ciudadanas inscritas en el Registro de Participación Ciudadana y de las personas físicas (...) llamadas a participar en la correspondiente convocatoria» (art. 14) y que debía recibir una respuesta afirmativa o negativa; la primera ocasión en que se pretendió utilizar este instrumento (Decreto 107/2014, de 2 de octubre, del Presidente del gobierno canario), entorno a la pregunta «¿Cree usted que Canarias debe cambiar su modelo medioambiental y turístico por las prospecciones de gas o petróleo?» (art. 5), el colectivo de personas físicas convocado fue, fundamentalmente, el de las personas residentes legalmente en las islas y mayores de dieciséis años (art. 3.1), las cuales podían emitir su respuesta a la pregunta planteada de forma presencial, en una fecha concreta, o mediante medios telemáticos, en un periodo algo más amplio. Como se ha indicado antes, ambos actos del ejecutivo canario (el Reglamento y la convocatorio del Decreto 107/2014) se encuentran suspendidos como consecuencia de la impugnación que el Estado presentó ante el TC. 
mentos de democracia directa como mecanismos de refuerzo de la democracia representativa, sin dejar de subrayar, no obstante, su carácter «especial o extraordinario por oposición al ordinario o común de la representación política», poniendo de relieve la naturaleza eminentemente representativa de la arquitectura institucional del sistema político español, en la que las instituciones de democracia directa (o semi-directa) adquieren una función eminentemente complementaria ${ }^{10}$. Al mismo tiempo, la repetida STC 103/2008 fue tajante al reiterar la jurisprudencia que establecía el instituto del referéndum, en tanto que interpelación directa al titular de la soberanía mediante un procedimiento electoral, junto a los propios comicios electorales como expresiones únicas del derecho de participación política ex art. 23.1 CE (por todas, STC 119/1995 FJ 6).

Precisamente, la STC 31/2015 (FJ 4) remite a esta doctrina para poner de relieve que el resto de consultas populares:

«no son expresiones del derecho de participación que garantiza el art. $23.1 \mathrm{CE}$, sino que obedecen a una ratio bien distinta. Se trata de manifestaciones que no son propiamente encuadrables ni en las formas de democracia representativa ni en la democracia directa, incardinándose más bien en un tertium genus que se ha denominado democracia participativa».

De donde se infiere que el género de las consultas populares se perfilaría, de una parte, como una suma de los instrumentos necesarios para el ejercicio

${ }^{10}$ La preeminencia de la democracia representativa en la doctrina constitucional arraiga parcialmente, como es sabido, en la prevención, cuando no desconfianza, con que fue tratada la fórmula del referéndum en el debate constituyente. Sin duda, la experiencia «plebiscitaria» del tardofranquismo condicionó al legislador constituyente y orgánico a la hora de prever, desarrollar y posteriormente aplicar la figura del referéndum. En este sentido, cabe recordar el antagonismo sobre las formas de democracia directa entre los representantes de la izquierda (SOLÉ TURA, entre otros), de una parte, y de otra la derecha, encarnada sobre todo por MANUEL FRAGA, partidario de un reconocimiento amplio de estos instrumentos. No deja de ser paradójico, con el recelo a la institución referendaria, el hecho de que el preámbulo de la Ley Fundamental exponga la necesidad de implantar con ella una democracia avanzada, además de que el artículo 9 incluya el derecho de participación y el 23 lo consagre como derecho fundamental. Para una referencia de los términos de los mencionados debates pueden consultarse la aportación del profesor OLIVER ARAUJO, J., «Encuesta sobre el referéndum», Teoría y Realidad Constitucional, núm. 30, 2012, pp. 21-24, y MARTíN NúÑEZ, E., «El referéndum y las consultas populares en las comunidades autónomas y municipios», Revista Vasca de Administración Pública, núm. 94, septiembre-diciembre, 2012, pp. 98-102). Esta renuencia de nuestra Norma Fundamental contrasta, vivamente, con el relieve y frecuencia que adquiere la fórmula referendaria en el ordenamiento jurídico de otras democracias consolidadas, así como con las recientes reivindicaciones, de amplios sectores sociales, por ejemplo, de una mayor participación directa de la ciudadanía en las decisiones públicas. 
de un derecho fundamental mediante el referéndum (art. 23.1 CE); y, por otra, que las formas de participación establecidas por el constituyente, «algunas de las cuales se convierten en verdaderos derechos subjetivos, bien ex constitutione, bien como consecuencia del posterior desarrollo por parte del legislador» (STC 31/2015 FJ 4) se incardinarían genéricamente en el mandato del art. 9.2 CE (STC 31/2015 FJ 5).

\subsection{La definición de la consulta referendaria en la jurisprudencia y la doctrina}

Sobradamente conocidos son los elementos de naturaleza orgánico-prodedimental que la STC 103/2008 estableció para atribuir la condición de referéndum a una consulta popular, esto es, la concurrencia de los siguientes tres requisitos: (1) que el sujeto consultado sea el cuerpo electoral; (2) que se conforme y se exteriorice como un procedimiento electoral; y (3) que cuente con garantías jurisdiccionales específicas. Así pues, el TC descartó explícitamente que el carácter vinculante o consultivo de la consulta tuviese la más mínima relevancia a los efectos taxonómicos. Esa definición es, además, la que ha integrado el núcleo argumental sobre el que ha ido evolucionando la jurisprudencia constitucional en la materia.

Ciertamente, la STC 103/2008 contiene otras consideraciones que hay que tener en cuenta, en especial, como señala CARRASCO DURAN ${ }^{11}$, en el ámbito material relativo a las cuestiones susceptibles de consulta referendaria. Con todo, parece discutible que las determinaciones que en este ámbito expresa la referida Sentencia permitan por sí mismas, cómo sostiene el citado autor, singularizar la especie referendaria dentro de las consultas populares. Parece indudable que al anteponer la definición orgánicoprocedimental el TC desaprovechó la oportunidad para establecer una caracterización más substantiva del referéndum, en la línea de la que había acogido la doctrina anterior. Así, por ejemplo, una relevante contribución de Bueno ARMiJo había subrayado el carácter político de la esencia del referéndum, dado que mediante esta figura se recaba, básicamente, la opinión directa y legítima de un sujeto político (el cuerpo electoral) ${ }^{12}$, algo que sólo puede hacerse mediante un proceso que observe los trámites y rituales equivalentes al electoral. Y ello no ocurriría en el resto de consultas populares, dado que en ellas se manifiesta la opinión de «ciudadanos concretos,

11 Vid. Carrasco Duran, M., «Referéndum versus consulta», Revista de Estudios Políticos, núm. 160, abril-junio, 2013, pp. 13-41.

${ }_{12}$ Una apreciación que también se encuentra en la STC 119/1995 (FJ 6), cuando se atribuye al referéndum la función de «conocer la voluntad de la generalidad de los ciudadanos (...) precisamente en lo que tiene de general». 
más o menos representativos del resto de sus conciudadanos o de específicos intereses de grupo o clase $\rangle^{13}$.

No en vano, pese a la voluntad de precisión a que apuntaba la STC $103 / 2008$, la definición de referéndum que la misma contenía fue objeto de críticas doctrinales muy tempranamente. En ellas, se reprochaban al Tribunal su falta de respuesta categórica a la cuestión de si cabía realizar una consulta no referendaria, sobre una cuestión de interés general formulada en determinadas condiciones, a través de la llamada al voto de un segmento de la población no coincidente con el censo electoral, pero suficientemente amplio para considerar el resultado como representativo del parecer del titular de la soberanía.

Así, para CASTELLÀ ANDREU, la STC 103/2008 contenía implícito el argumento de que el elemento distintivo del referéndum es la consulta mediante el voto, ya que establecía que el rasgo distintivo de las consultas populares no referendarias es que en ellas «[...] se recaba la "opinión", y para ello no hay ni sujetos -pueden ser individuos o colectivos-, ni procedimiento ni objeto formalizado de forma predeterminada. [...] Lo que importa es que la opinión se expresa a través de mecanismos distintos del voto (deliberación, encuesta)». Y todo ello, pese a reconocer que este principio hubiese podido expresarse de mejor forma por parte del $\mathrm{TC}^{14}$.

Con mayor énfasis se ha expresado IBÁÑEZ MACíAS, quien atribuye directamente a la argumentación del Alto Tribunal la responsabilidad de abrir la posibilidad de establecer legislativamente las consultas populares no referendarias mediante votación de un conjunto general de la ciudadanía, al favorecer la contradicción sistemática de los rasgos definitorios del referéndum en la STC 103/2008: «[...] ha abierto esta posibilidad y tendrá que ser él quien la cierre, afinando la distinción entre consulta popular y referéndum $\rangle^{15}$. La raíz del problema, según el citado autor, se encuentra en el erróneo criterio de definición del referéndum empleado por el TC, para lo cual propone una corrección:

«[...] lo relevante para concluir que una consulta popular determinada es un referéndum no es el voto en la urna [...]; ni que se use el censo (aun-

13 Vid. BuEno ARMiJo, A., “"Consultas populares” y "referéndum consultivo": una propuesta de delimitación conceptual y de distribución competencial», Revista de Administración Pública, núm. 177, septiembre-diciembre, 2008, pp. 195-228.

14 Vid. CAStellà Andreu, J. M., «Consultas populares no referendarias en Catalunya ¿Es admisible constitucionalmente un tertium genus entre referéndum e instituciones de participación ciudadana?». Monografías de la Revista Aragonesa de Derecho Público, XIV, 2013, pp. 121-155.

15 Vid. IBÁÑEZ Macías, A., «Los referendos regional y local en el Estado Autonómico. Sus bases y límites constitucionales», Revista Vasca de Administración Pública, núm. 97, septiembre-diciembre, 2013, p. 103. 
que se use el padrón municipal, seguirá siendo un referéndum, aunque ilegal); ni que se utilicen las garantías previstas en la LOMR o en la LOREG [...]. Lo importante es que se esté ante una forma de participación política incluida en el artículo 23.1 CE. Una forma de participación es política $[. .$.$] porque en ella se participa uti cives, es decir, como miembro$ de una colectividad territorial. No lo es cuando se participa a titulo individual (como interesado en un procedimiento administrativo, uti singulis) o como miembro de una asociación o de una categoría social o profesional (uti socius)» ${ }^{16}$.

El cierre de ésta controversia ha tenido lugar, finalmente, en la STC $31 / 2015$, la cual zanja definitivamente esta cuestión al considerar que:

«estamos ante un referéndum cuando el poder público convoca al conjunto de los ciudadanos de un ámbito territorial determinado para que ejerzan el derecho fundamental de participación en los asuntos públicos emitiendo su opinión, vinculante o no, sobre una determinada cuestión, mediante votación y con las garantías propias de un proceso electoral» (FJ 6).

Y todo ello tras de realizar una matización substancial en la doctrina de la STC 103/2008, al añadir a la definición orgánico-procedimental una alusión, ciertamente algo confusa, a la distinción uti cives/uti singulis/uti socius (IвÁÑEZ MACíAS), cuando subraya el carácter del referéndum como expresión de la opinión del cuerpo electoral, el cual se identifica con el sujeto que expresa la voluntad del pueblo ${ }^{17}$, y principalmente al explicitar que:

«[u]n segundo elemento ínsito en el concepto de referéndum estriba en que la opinión del cuerpo electoral se expresa por medio del sufragio emitido en el curso de un proceso electoral, a fin de que el resultado de la consulta pueda jurídicamente imputarse a la voluntad general de la correspondiente comunidad política y, de este modo, considerarse una genuina manifestación del derecho fundamental de participación política reconocido en el art. 23.1 CE» (STC 31/2015 FJ 5).

\footnotetext{
${ }^{16}$ Cfr. Ibídem, p. 104.
}

17 Esta argumentación remite a las SSTC 12/2008 (FJ 10) y 31/2010 (FJ 69). El TC ha aclarado que «el cuerpo electoral no se confunde con el titular de la soberanía, esto es, con el pueblo español (art. 1.2 CE). Este cuerpo electoral está sometido a la Constitución y al resto del Ordenamiento jurídico (art. 9.1 CE), en tanto que el pueblo soberano es la unidad ideal de imputación del poder constituyente y como tal fundamento de la Constitución y del Ordenamiento» (STC 13/2009, FJ 16). Conviene recordar, sin embargo, que las SSTC 12/2008 y 13/2009 hacen referencia a una cuestión relativa al sufragio pasivo (art. 23.2 CE) a propósito de las cuotas de género en las listas electorales (Disposición adicional $2^{\mathrm{a}}$, Ley Orgánica 3/2007 y la Ley del Parlamento Vasco 4/2005, respectivamente). 


\subsection{La definición de la consulta popular no referendaria por exclusión: el ejemplo de la Ley del Parlamento de Catalunya 10/2014}

Como ya se ha expuesto, la jurisprudencia constitucional previa a la STC $31 / 2015$ se empleó con mayor intensidad en la definición de las consultas referendarias, dejando el resto de consultas populares en una zona más lábil o difusa, en buena parte debido a la omisión de los rasgos formales que concurren entorno al referéndum. En estas condiciones, la mera deducción de que son consultas populares no referendarias todas aquellas que no detentan ninguno de los elementos orgánico-procedimentales que singularizan el instituto referendario, era demasiado obvia como para no ser acogida por una parte de la doctrina $\mathrm{y}$, como hemos visto, por algunos legisladores autonómicos. Pero, más aún. Es el propio TC el que pareció acogerse a ella cuando argumentó que:

«Caben, pues, consultas populares no referendarias mediante las cuales "se recaba la opinión de cualquier colectivo sobre cualesquiera asuntos de interés público a través de cualesquiera procedimientos" distintos de los que cualifican una consulta como referéndum [...]. Si a ello se añade que las consultas previstas en el precepto se ciñen expresamente al ámbito de las competencias autonómicas y locales, es evidente que no puede haber afectación alguna del ámbito competencial privativo del Estado» (STC 31/2010 FJ 69).

Así, en referencia específicamente a las consultas populares no referendarias mediante el voto de la ciudadanía, el InstituT D'Estudis AUTONÒMICS reiteró su opinión de que la existencia de título competencial expreso es suficiente para garantizar la constitucionalidad de la regulación de consultas populares no referendarias que presenten una diferenciación de la literalidad de los criterios enunciados en la STC 103/2008, manteniendo unas garantías equivalentes de transparencia y seguridad de la consulta ${ }^{18}$. Y, por su parte, MARTíN NÚÑEZ caracterizó el referéndum como una llamada al cuerpo electoral en unos términos semejantes al ejercicio del derecho del sufragio, al deducir que si la llamada se realizase a un censo poblacional diferente del electoral sería posible la figura de una consulta no referendaria mediante el voto, si bien admitiendo, en la línea de la jurisprudencia del TC, que esas

18 Ya durante los trabajos preparatorios del EAC 2006, un informe preliminar elaborado por el INSTITUT D'ESTUDIS AUTONÒMICS (2003) sugirió la posibilidad de incluir explícitamente en el nuevo texto estatutario una modalidad de consulta popular distinta del referéndum para recabar «el parecer ciudadano sobre cuestiones de interés general en materias autonómicas o locales», aplicando una «interpretación flexible» del art. 149.1.32 $\mathrm{CE}$, que permitiese distinguir este tipo de consultes del referéndum, de acuerdo con el principio participativo ex art. 9.2 CE. Vid. InstiTuT D'EsTUdis AutonÒMICS, Informe sobre la reforma de l'Estatut, 2003, p. 196. <http://www.gencat.cat/drep/iea/sumaris/re1. pdf $>$ (última consulta: 30 abril 2015). 
eventuales consultas no tendrían la consideración de expresión del derecho de participación política directa (ex art. $23 \mathrm{CE}$ ), contrayéndose, por tanto, a la canalización de fórmulas de democracia participativa ${ }^{19}$.

No obstante, una buena parte de la doctrina continuó refractaria a aceptar la constitucionalidad de cualquier forma de consulta popular mediante el voto o que implicase que el ejercicio del derecho de participación política utis civie puediera ser considerado al margen del instituto referendario, por entender que cualquier intento de configurar un instrumento semejante, mediante el sorteo de los límites literales establecidos en la STC 103/2008, constituye una utilización inapropiada del mismo, cuando no un fraude de $1 \mathrm{y}^{20}$. En ese sentido, a la vista del cuadro constitucional y estatutario, CASTELLÀ ANDREU aprecia inviable:

«[F]orzar los márgenes del referéndum a través del diseño de una figura que sustancialmente lo recuerda, aunque trate de disimularlo. El referéndum es una institución que tiene una configuración general ya consolidada, cuyos rasgos identificadores no dependen de estar previsto o no en la Constitución, de tener efectos vinculantes o no, o de requerir su convocatoria la autorización del Estado, pues son elementos externos a la propia figura, que sirven para caracterizar el régimen constitucional del referéndum, pero no la identificación de la misma institución jurídica. Por otro lado, tampoco cabe forzar el sentido de las competencias propias de la Generalitat, estatutariamente previstas ${ }^{21}$.

En este contexto, el Parlamento de Cataluña, aprobó la Ley 10/2014, de consultas populares no referendarias y participación ciudadana, en desarrollo de los arts. 29.6 y $122 \mathrm{EAC}^{22}$. En síntesis y por lo que hace a los aspectos que

${ }^{19}$ Cfr. op. cit, 2012, p. 117.

${ }^{20} C f r$. IBÁÑ̃z MaCíAS, A., «Los referendos regional y local en el Estado Autonómico. Sus bases y límites constitucionales», op. cit. p. 103.

${ }^{21}$ Cfr. op. cit. p. 152.

${ }^{22}$ Cabe recordar que el tortuoso proceso que condujo a la aprobación de la Ley 10/2014 no siempre estuvo vinculado, por lo menos explícitamente, a lo que luego se conoció como «proceso para el ejercicio del derecho a decidir». Sus antecedentes hay que buscarlos en las enmiendas que, durante la tramitación de la que luego sería aprobada como Ley de Catalunya 4/2010 de consultas populares por vía de referéndum, presentó el grupo parlamentario de Convergència i Unió (CiU) con la pretensión de desarrollar, simultáneamente, la figura de las consultas no referendarias (Butlleti Oficial del Parlament de Catalunya [BOPC], VIII legislatura, núm. 540 de 28.09.2009). En la legislatura siguiente, el gobierno de CiU aprobó, durante la IX legislatura catalana, un Proyecto de ley de consultas populares no referendarias (BOPC, IX legislatura, núm. 222 de 11.01.2012), que decayó por la disolución anticipada de la cámara. Después de las elecciones, el programa contenido en el Acuerdo de Gobernabilidad CiU-ERC retomó la iniciativa (BOPC, X legislatura, núm. 50 de 27.03.2013), ahora sí explícitamente incluida dentro del «derecho a decidir», ultimando la tramitación. 
son más relevantes para este trabajo, la Ley catalana se elaboró, en la materia relativa a las consultas populares no referendarias mediante el voto, que el texto contemplaba en las dos modalidades de generales y sectoriales (art. 3), con la sistemática transposición a sensu contrario de los criterios enunciados en la STC 103/2008 para la identificación de un referéndum.

Así, por ejemplo, en las consultas generales el cuerpo electoral era substituido por el concepto de «personas legitimadas» (art. 5), que consistía, básicamente, en el conjunto de personas que integrarían el censo electoral en unas elecciones municipales, ampliado a los jóvenes de edad entre 16 y 17 años y las personas originarias de países ajenos a la Unión Europea (UE) con más de tres años de residencia continuada. El sistema de garantías procedimentales y jurisdiccionales del proceso se estructuraba de forma paralela al procedimiento electoral (en este caso, con una Comisión de Seguimiento y una Comisión de Control, atribuidas de funciones de sindicatura electoral). Incluso se contemplaba la asignación de espacios en medios de comunicación públicos (art. 22). En cuanto a los efectos, se disponía que no era otro que conocer la opinión de la población sobre la cuestión sometida a consulta, cuyo resultado no tenía carácter vinculante, pese a que todos los poderes públicos que los convocasen debían pronunciarse sobre la incidencia de la misma en su actuación pública.

Como es sabido, en la STC 31/2015, emitida en respuesta a la impugnación de la Ley catalana 10/2014, el Alto Tribunal verificó un juicio del citado texto normativo prescindiendo totalmente del nomen iuris asignado a las consultas reguladas por dicha ley, pues «ni un referéndum dejará de serlo tan sólo porque la norma legal que lo prevea le niegue la condición de tal, ni el derecho ex art. 23.1 CE a la participación directa en los asuntos públicos perderá su fuerza vinculante porque la ley, de nuevo, niegue haber procedido a su regulación o desarrollo» (FJ 7). De esta forma, el TC concluyó que las llamadas «consultas generales» en la Ley 10/2014 son verdaderos

«llamamientos para la participación política, a través de un procedimiento electoral, de un cuerpo de electores que vendría así a expresar, mediante el sufragio, el parecer de los ciudadanos de Cataluña en el ejercicio del derecho reconocido en el art. 23.1 CE y no como meros administrados. En ese cuerpo electoral sui generis (...) está sin duda comprendido o integrado el electorado, estatutario y legal, de Cataluña (...). Por ello, y aun cuando una determinada consulta general se acotara, exclusivamente, a las "personas legitimadas" (...), estaría siendo convocado a las urnas el cuerpo electoral de Cataluña, o de la correspondiente entidad local, aunque no sólo él» $(\mathrm{FJ} 8)^{23}$.

${ }^{23}$ El TC prosigue su argumentación: «Es, por tanto, un llamamiento a un cuerpo electoral más amplio que el configurado por la legislación electoral general, pero que no 
El TC añadió que, según su parecer, bajo la rúbrica «Procedimiento de las consultas populares no referendarias» la ley catalana estaba regulando un procedimiento electoral articulado en torno una serie de elementos mediante los cuales se venía a «configurar (...) un procedimiento que tiene la naturaleza de electoral en la medida en que a través del mismo se canaliza el ejercicio del derecho al sufragio activo de las personas convocadas, mediante la emisión del voto» (FJ 8).

Sin embargo, debe decirse que la revisión del aparato argumental exhibido por el propio TC (singularmente las 103/2008 y 31/2010), aquí lastrada por la fundamentación orgánico-procedimental de las mismas, no deja de traslucir una cierta tosquedad. Así, por ejemplo, el insistente recurso a poner de relieve que el colectivo de las «personas legitimadas» en realidad incluye, como un subconjunto, el censo electoral, plantea la duda de si la conclusión del Alto Tribunal hubiese sido distinta en caso de que, por ejemplo, los llamados al voto hubiesen sido sólo las personas mayores de 21 años. Por otro lado, la insistencia en la exclusión de la inconstitucionalidad de las consultas que califica de sectoriales, pese a que la Abogacía del Estado no trasladó a su juicio de constitucionalidad el contenido de esta distinción (FJ 7), son un claro ejemplo del magro razonamiento competencial contenido en su anterior jurisprudencia (vgr. STC 31/2010, FJ 69). Así, el TC resalta que:

«las consultas sectoriales reguladas en la misma Ley presuponen el llamamiento a un sujeto jurídico más restringido que el cuerpo electoral, en cuanto articulan voluntades particulares o colectivas, pero no generales, esto es, no imputables al cuerpo electoral, por lo que son cauces de participación cuya regulación por el legislador autonómico catalán resulta posible en consideración al título competencial establecido en el art. 122 EAC» (STC 31/2015 FJ 9).

El reproche de constitucionalidad que la STC 31/2015 aprecia en las consultas generales que establece la Ley catalana 10/2014 se extiende a la

por ello deja de ser una verdadera apellatio ad populum. La circunstancia de que la consulta pueda extenderse a menores de dieciocho años y a los nacionales de Estados miembros de la Unión Europea o de terceros Estados, no obsta para que sus resultados sean imputables al parecer de la ciudadanía de la Comunidad Autónoma y considerarse expresivos de su voluntad general en relación con los asuntos que se les planteen en cada caso. El cuerpo electoral conformado en el art. 5.1 de la Ley, aunque lo desborda, abarca al conjunto de la ciudadanía de la Comunidad Autónoma de Cataluña o del ente territorial local, cuyos sufragios no exteriorizan meras voluntades particulares o de colectivos sectoriales sino su voluntad general uti cives. En cualquier caso, los menores de 18 años son convocados en su condición "política" de catalanes y los extranjeros en cuanto "nacionales" de otros Estados, es decir, en la condición más genérica de ciudadanía que les es aplicable» (STC 31/2015 FJ 8). 
totalidad de las modalidades de consulta general previstas en la Ley, incluidas la de ámbito local y supramunicipal ${ }^{24}$. El TC argumenta, de una forma un tanto sumaria, que la verdadera naturaleza referendaria de unas consultas populares que, de forma expresa, no deberían serlo, vicia de inconstitucionalidad la entera categoría de las consultas generales ${ }^{25}$. Cabe entender aquí que el carácter referendario aplicado a las consultas locales se entiende referido a la preceptiva autorización estatal, pues como hemos citado en reiteradas ocasiones aquí, la doctrina sustrae la naturaleza referendaria de estas consultas.

Adicionalmente, el TC establece (FJ 10) una cautela complementaria para la exclusividad de la competencia atribuida en el art. 122 EAC respecto de las consultas sectoriales de ámbito local, la cual deberá ser ejercida sin perjuicio de la competencia estatal sobre las bases del régimen jurídico de las Administraciones públicas (art. 149.1.18 CE).

En suma, la STC 31/2015 cierra de forma abrupta la ventana legislativa que buena parte de la doctrina entendió abierta a partir de la literalidad de la propia STC 103/2008, aduciendo que no cabe, en el ordenamiento constitucional, ninguna otra llamada distinta de la vía referendaria para compulsar la opinión de la ciudadanía en torno a cualquier cuestión de relevancia política, mediante la emisión del voto. Ello implica, pues, el necesario sometimiento a la autorización estatal previa (art. 149.1.32 CE), al igual que acontece en otras consultas mediante el voto de la generalidad de la población, formalmente diferenciadas de los referéndums, como las consultas locales.

\section{LAS COMPETENCIAS DE LA GENERALITAT EN MATERIA DE CONSULTAS POPULARES}

\subsection{Las consultas populares en el Estatuto de 2006 y su desarrollo. El efecto de la STC 31/2010}

Aunque, como hemos señalado anteriormente, el referéndum autonómico carece de anclajes en la legislación estatal, su figura no fue ignorada en el

${ }^{24}$ Arts. 3.2 (en su inciso relativo a los entes locales), 4.3, 10, 12 y 38 de la Ley 10/2014. En relación a las consultas de ámbito supramunicipal, la Abogacía del Estado planteó específicamente su nulidad al carecer de cobertura contitucional o en la legislación básica estatal (art. 71 LRBRL), pero el TC no entra específicamente en la valoración del argumento.

25 «(...) todas las consultas generales reguladas en la Ley catalana 10/2014, de 26 de septiembre, cualquiera que sea el ámbito territorial en el que pretendieran celebrarse (autonómico, municipal o supramunicipal), son inconstitucionales -por su carácter referendario» (STC 31/2015 FJ 10). 
debate constituyente ${ }^{26}$, además de que, como ha señalado acertadamente MARTíN NÚÑEZ ${ }^{27}$, tanto la mera previsión de autorización estatal previa (art. 149.1.32 CE), como la ubicación de la misma en la norma constitucional (precisamente en el artículo que deslinda las competencias entre el Estado y las CA), carecerían de sentido si no se hubiese pretendido remarcar que el requisito de la autorización tiene como objeto preferente las consultas populares por vía de referéndum que puedan proponer eventualmente las Comunidades Autónomas dentro de su ámbito territorial.

No obstante lo dicho, la ausencia de previsión constitucional específica y, más concretamente, en la LORMR, sobre los referéndums de alcance autonómico, no debería impedir que estos pudiesen ser regulados en caso de existir base competencial, del mismo modo que sucede con la Iniciativa Legislativa Popular (ILP), igualmente considerada un mecanismo de participación política directa de los ciudadanos conectado con el artículo $23.1 \mathrm{CE}^{28}$.

Al mismo tiempo, la indeterminación constitucional y legal del referéndum consultivo ex artículo $92 \mathrm{CE}$, al no especificar su ámbito de aplicación, permite pensar en la convocatoria del mismo en diferentes ámbitos territoriales, incluido el autonómico, siempre que se preserve la adecuada correspondencia entre el contenido y alcance de la consulta. Recuérdese a este respecto que tanto el artículo 92.3 (la previsión de Ley orgánica) como el acto regio de convocatoria (art. $62 c \mathrm{CE}$ ) tienen el carácter de normas de reenvío y, por definición, se hallan abiertas a otros tipos de referendos que los expresamente previstos en la Constitución.

De ahí que una interpretación de este tenor podría inspirar y legitimar una reforma de la LORMR, con la incorporación de algún precepto referido expresamente a los de alcance autonómico, habilitando así el rango de norma-

${ }^{26}$ Durante la redacción constitucional se excluyó, también, la incorporación al texto del instituto del referendo autonómico, al rechazarse una enmienda presentada, con ese objeto, por el Grupo de Socialistas Vascos en el Senado, más allá de los casos expresamente establecidos en la CE.

${ }^{27}$ Cfr. op. cit. pp. 109-110.

${ }^{28}$ En este sentido, no deja de ser paradójico el citado ejemplo de la ILP (art. 87.3 CE), sobre el que la Constitución establece una reserva de ley orgánica y no por ello la mayor parte de CA han dejado de desarrollarlo. Aunque más paradójico resulta el examen de la disposición adicional (DA) de la vigente LORMR, que excluye de su ámbito de aplicación las consultas que puedan celebrar los ayuntamientos, salvo la competencia exclusiva del Estado para su autorización (MARTín NúÑEZ, 2010: pp. 320-321). Además, la LRBRL, sin tener rango de orgánica, y respetando las competencias autonómicas, ya regula los referéndums consultivos de los ayuntamientos para los asuntos de su competencia y de carácter municipal. Estirando el hilo de este argumento, no hay duda de que una reforma de la LORMR para incorporar las consultas autonómicas por vía de referéndum permitiría eludir la interpretación restrictiva de la STC 31/2010. 
tiva general a la que someter la legislación autonómica. No sería preciso llegar a esta modificación si se interpretara alternativamente la referencia del artículo 92.1 CE («todos los ciudadanos») en el sentido de que la participación de todos los ciudadanos españoles no tiene por qué influir en la valoración política de los resultados obtenidos en una concreta Comunidad Autónoma $^{29}$. En ese caso parecería suficiente la incorporación de una disposición adicional ad hoc para excluir la aplicación de esta ley a los referéndums autonómicos, de manera análoga a la existente para las consultas de ámbito local.

En este contexto, la previsión del Estatuto de Autonomía de Catalunya de 2006 (EAC) en materia de las consultas populares (art. 122) partía de la convicción, discutible, pero legítima, de que la recepción del referéndum en el ordenamiento jurídico español no queda circunscrita al marco estatal, sino que constituye un elemento vinculado al Estado autonómico, interpretando de ese modo que la competencia estatal para autorizar la convocatoria debería permitir a la Generalitat de Cataluña regular tanto la iniciativa como el procedimiento previo a la convocatoria ${ }^{30}$. Dicha lectura, se amarraba, además de a la existencia de consultas de ámbito local, en una interpretación amplia del principio democrático (art. 1.1 CE) y del derecho fundamental de participación política de la ciudadanía (art. $23 \mathrm{CE})^{31}$.

Así las cosas, el EAC configuró, primero, como derecho estatutario, el derecho de participación que se atribuía a los ciudadanos, y dentro de éste, del derecho a elaborar, participar y promover la convocatoria de consultas populares en el ámbito de las competencias de la Generalitat y de los ayuntamientos (art. 29); para asumir, posteriormente, la competencia exclusiva en materia de «consultas populares» (art. 122), en despliegue del derecho fundamental del artículo $23 \mathrm{CE}$. El legislador estatutario distinguió así, por un lado, entre el género «consultas populares», entendido

${ }^{29}$ Aguiar de Luque, L. defiende, incluso, la legitimidad de convocar directamente referéndums del artículo $92 \mathrm{CE}$ en el ámbito territorial autonómico, por entender que la locución «de todos los ciudadanos» no va dirigida a delimitar el alcance exacto de estos referéndums y porque, además, la regulación incluida en la LORMR no es mucho más precisa en ese sentido («Democracia directa e Instituciones de democracia directa en el ordenamiento constitucional español», en TRUJILlo, LóPEZ GUERRA, GonZÁLEZ-TREVIJANO (Dir.): La experiencia constitucional (1978-2000), CEPC, Madrid, 2000, págs. 67-96).

30 Vid. MARTín NúÑEz, E., «Comentari a la Sentència sobre l'Estatut. Competència en matèria de consultes populars (art. 122)», Revista catalana de dret públic, número especial Sentencia 31/2010 del Tribunal Constitucional sobre el Estatuto de Autonomía de Cataluña de 2006, 2010, p. 321.

${ }^{31}$ Esta argumentación subyace en las potestades sobre regulación de la iniciativa legislativa popular y legislación electoral propia, desplegadas de forma constitucionalmente pacífica por distintas Comunidades Autónomas. 
como el conjunto de instrumentos de participación ciudadana dirigidos a conocer la opinión de la ciudadanía en relación con cualquier aspecto de la vida política, que se materializan a través de diversas modalidades; y por otro lado, la especie concreta de las realizadas por vía referendaria, a las cuales no se refería con la denominación específica «referéndums», sino identificada con la modalidad de consulta popular que requiere la autorización del Estado. Por otro lado, la regulación estatutaria arrancaba también del hecho de que el referéndum autonómico constituye una concreción de la forma institucional de gobierno representativo diseñada para las CCAA (art. 147 y $152 \mathrm{CE}$ ), insertable en la potestad de autoorganización (art. 148.1.1 CE) ${ }^{32}$. Pues, en efecto, la lectura del art. $152 \mathrm{CE}$ permite inferir que las consultas populares se integran en el ámbito de la organización de las instituciones de autogobierno porque el modelo de organización territorial del Estado posibilita no sólo la distribución territorial del poder político, sino también la instauración de un nuevo ámbito de relaciones entre la sociedad y éste.

Con este convencimiento y en desarrollo del artículo 122 EAC, el Parlamento de Cataluña aprobó la Ley 4/2010 de consultas populares por vía de referéndum de Cataluña, de aplicación tanto a las consultas promovidas por las instituciones públicas (Parlamento, Gobierno o municipios), como a las de iniciativa ciudadana, en ejercicio del derecho estatutario de participación (art. 29 EAC). Su contenido concreto transponía, de forma bastante mimética, la doctrina constitucional sobre la materia -incluido, claro está, el sometimiento a la preceptiva y previa autorización estatal-, principalmente la contenida en la referida STC 103/2008 ${ }^{33}$.

Sin embargo, en su Sentencia sobre el EAC (STC 31/2010), el TC ya realizó una interpretación estricta del artículo 122 EAC, partiendo a su vez de una también rigurosísima lectura de la voluntad del constituyente a la hora de regular el instituto del referéndum, atribuyendo en exclusiva al Estado, no sólo la potestad de autorización, sino también la capacidad de establecer el régimen jurídico de las mismas («la entera normación»), a través de una ley orgánica ad hoc. Así, el FJ 69, afirma que

${ }^{32}$ Este fue, de hecho, uno de los argumentos centrales de la defensa de la Ley vasca 9/2008 utilizados por la Comisión Jurídica Asesora de Euskadi en su Dictamen 96/2008 (Párrafos 50-51).

${ }^{33}$ Pese a ello, la administración del Estado impugnó la norma, si bien, al término del plazo inicial de suspensión, el TC acordó levantar la suspensión (ATC 87/2011), aunque conviene recordar que, en este tipo de incidentes, el TC no entra a valorar el fondo del recurso, sino que se limita a argumentar sobre los previsibles perjuicios derivados del mantenimiento o levantamiento de la suspensión. Así las cosas, lo substantivo del pronunciamiento del TC es que la Ley 4/2010 está plenamente vigente en el momento en que se escribe este trabajo. 
«la exclusividad del art. 122 EAC tiene que serlo [...] sin perjuicio de la competencia estatal relativa a las bases del régimen jurídico de las administraciones públicas» (art. 149.1.18 CE); que la cláusula residual de este precepto («cualquier otro instrumento de consulta popular») no se tiene que entender como un referéndum; y que la autorización estatal para la convocatoria de la consulta, no es la única facultad que tiene el Estado en esta materia sino que alcanza «la entera disciplina de esta institución, esto es, su establecimiento y regulación» ${ }^{34}$.

Así, a pesar de que la STC 31/2010 no ocluye totalmente el paso al referéndum autonómico, ni al hecho que los estatutos puedan reconocer competencias en esta materia, su interpretación, prima facie, deja hoy por hoy sin demasiada cobertura competencial a cualquier ley autonómica sobre la materia. Abundando en la materia, precisamente la más reciente STC 31/2015 deshabilitó la posibilidad de instrumentar una vía alternativa de consulta popular mediante votación alternativa no sometida al rígido corsé constitucional del referéndum. De esta forma, el TC se alineó con las interpretaciones doctrinales que, a partir de una lectura estricta de la STC 103/2008, invalidaban la posibilidad en la práctica de toda consulta referendaria autonómica al margen de las establecidas en la CE y la LORMR ${ }^{35}$.

\subsection{La matización de las restricciones a la capacidad autonómica en la STC $42 / 2014$}

Con fecha 25 de marzo, el TC emitió la sentencia 42/2014 sobre la Resolución 5/X del Parlament ${ }^{36}$, por la que declaró inconstitucional y nula la

${ }^{34}$ Una cronología de los actos puede ser útil para entender el encadenamiento de los mismos: la Ley 4/2010 fue aprobada por el Parlament el 17.03.2010 y la STC 31/2010 sobre el EAC fue aprobada por el Alto Tribunal en su sesión de 28.06.2010. Cabe plantear una duda razonable sobre la ultimación de la Ley 4/2010 en caso de haberse conocido el contenido de la STC 31/2010 durante su tramitación.

35 Vid. Fondevila Maron, M., «Derecho a decidir y soberanía. A propósito de la sentencia 42/2014, de 25 de marzo», Teoría y Realidad Constitucional, UNED, Madrid, núm. 34, 2014, p. 598.

36 Durante el primer pleno de la X legislatura catalana, el 23 de enero de 2013, se aprobó la Resolución 5/X bajo la rúbrica «Declaración de soberanía y del derecho a decidir del pueblo de Catalunya», en la cual se afirmaba, en esencia, que «[E]l pueblo de Catalunya tiene, por razones de legitimidad democrática, carácter de sujeto político y jurídico soberano», como fundamento para «iniciar el proceso para hacer efectivo el ejercicio del «derecho a decidir». Expresada en sus términos estrictos, la Resolución 5/X era una inequívoca declaración «política» de signo soberanista, sin que ello implicase el ejercicio de la «soberanía del pueblo catalán» en un acto concreto y concluyente, con efectos jurídicos vinculantes; es más, la Resolución «tampoco prejuzga en ningún momento que el objetivo de la proclamación del derecho a decidir sea la constitución de un estado propio 
cláusula primera de la mencionada Resolución, al entender que el reconocimiento que en ella se realizaba del pueblo de Cataluña como «sujeto político y jurídico soberano» resultaba contrario a los arts. 1.2 y $2 \mathrm{CE}$ y a los arts. 1 y 2.4 $\mathrm{EAC}^{37}$, así como, en relación con ellos, a los arts. 9.1 y $168 \mathrm{CE}$.

La STC 42/2014 incorporó no obstante un reconocimiento novedoso y transcendente del encaje constitucional del llamado "derecho a decidir», como una aspiración política legítima que puede amparar la realización de actividades dirigidas a «preparar» o «defender» la separación de Cataluña e incluso a instar la «consecución efectiva» de ese objetivo en el marco de los procedimientos de reforma de la Constitución ${ }^{38}$, atendiendo a la conocida doctrina de la plena tangibilidad de las disposiciones constitucionales, distinguiendo, de forma algo heterodoxa, entre el derecho a la autodeterminación y el derecho a decidir.

En efecto, el TC entiende el primero de estos derechos como la capacidad para decidir de manera directa y jurídicamente efectiva la integración territorial de España, lo cual, como tal, no está reconocido en la Constitución española para los territorios integrantes del Estado. Y, por el otro, concibe el derecho a decidir como la capacidad para manifestar «una aspiración política» que, si es canalizada «mediante un proceso ajustado a la legalidad constitucional», se estima que tiene cabida en el marco de la Constitución. Para el Alto Tribunal, el derecho a decidir no es un derecho a la autodeterminación, pero tiene sustantividad propia. Constituye una legítima aspiración política

o la independencia de Catalunya». (Vid. VinTró CAStells, J., «La Declaració de sobirania i del Dret a decidir del poble de Catalunya: un apunt jurídic», Blog de la Revista Catalana de Dret Públic, 7 de febrer, <http://blocs.gencat.cat/blocs/AppPHP/eapcrcdp/2013/02/07la-declaracio-de-sobirania-i-del-dret-a-decidir-del-poble-de-catalunyaun-apunt-juridic-joan-vintro/> (Consultado el 20.04.2015).

37 En particular, la Sentencia señaló que «el reconocimiento al pueblo de Cataluña de la calidad de soberano, no prevista en nuestra Constitución para las nacionalidades y regiones que integran el Estado, resulta incompatible con el art. $2 \mathrm{CE}$, ya que supone conferir al sujeto parcial del que se predica esta calidad el poder de romper, por su sola voluntad, lo que la Constitución declara como su propio fundamento en el citado precepto: «la indisoluble unidad de la Nación española». Como realidad sociohistórica, Cataluña (y España toda) -aduce el TC- es anterior a la Constitución de 1978. Sin embargo, desde el punto de vista jurídico-constitucional, el pueblo de Cataluña invocado por la Declaración es «un sujeto que se constituye en el mundo jurídico en virtud del reconocimiento constitucional (al igual que sucede con el conjunto del "pueblo español" del que, según el art. 1.2 CE, emanan todos los poderes del Estado)».

${ }^{38}$ El TC argumenta en su Sentencia una lectura constitucional del «derecho a decidir», entendido como «una aspiración política a la que se llegue mediante un proceso ajustado a la legalidad constitucional», con respeto a los principios de «legitimidad democrática», «pluralismo»y «legalidad», principios que el texto reconoce expresamente proclamados en la Resolución 5/X del Parlament. 
amparada - en un ordenamiento constitucional de democracia no militante, como el propio Tribunal reitera en la sentencia-por la libertad de expresión y, en términos más amplios, de participación, en el ámbito político, que puede llegar a sustentar la propuesta de modificación de la Constitución.

No toda la doctrina ha estado de acuerdo con la interpretación del TC en este punto. FossAS, por ejemplo, reprochó al Tribunal una cuestionable aplicación de la técnica de la interpretación conforme, que «reconstruye el texto de la Resolución para convertir una consigna política en un derecho hasta hoy inexistente», y no sólo eso sino que «consagra "el derecho a decidir" como algo distinto del derecho a la autodeterminación ${ }^{39}$. Sin embargo, lo cierto es que la STC 42/2014 declara, inequívocamente, que los poderes públicos pueden realizar actividades de defensa y preparación del ejercicio del derecho a decidir y que ello, de entrada, tiene efectos jurídicos prácticos muy relevantes ya que pueden legitimar constitucionalmente las medidas que han ido adoptando no sólo varios colectivos y organizaciones sociales, en tanto que entidades privadas, sino también los poderes públicos en Cataluña, y especialmente la Generalitat $^{40}$. Por su parte, SolozABAL ECHAVARRía señaló que, en tanto que el derecho a decidir, como aspiración política, no puede llevarse a cabo sin reformar la Constitución, ello implica una disposición del orden constitucional al alcance sólo del poder constituyente, de modo que «no queda, quizás, mucho espacio para entender tal derecho fuera de su versión banalizada como derecho de participación, directa o a través de representantes $\rangle^{41}$.

\section{LAS MATERIAS SUSCEPTIBLES DE SER OBJETO DE CONSULTA: JURISPRUDENCIA Y DOCTRINA}

Como ya ha sido dicho, la singularidad del referéndum dentro del género consultas populares alcanza también a su ámbito material, dado que un sector

39 Vid. Fossas EsPadaler, E., «Interpretar la política. Comentario a la STC 42/2014, de 25 de marzo, sobre la Declaración de soberanía y el derecho a decidir del pueblo de Cataluña», Revista Española de Derecho Constitucional, núm. 101 (mayo-agosto), 2014, p. 300 .

${ }^{40}$ Así, por ejemplo, la creación del Consell Assessor per a la Transició Nacional (CATN), como la de otros organismos establecidos por la Generalitat, quedan definitivamente legitimados desde el punto de vista constitucional. Igualmente quedan legitimadas de manera incontrovertible las declaraciones y manifestaciones realizadas en defensa del ejercicio del derecho a decidir que se han llevado a cabo y las que se puedan llevar a cabo en el futuro, mientras respeten, como dice la sentencia, los principios democráticos, los derechos fundamentales y el resto de los mandatos constitucionales.

${ }^{41}$ Vid. SOlOzABAL EChaVARRíA, J. J., «La sentencia sobre la declaración soberanista y el derecho a decidir del pueblo catalán (STC 42/2014)», El Cronista del Estado Social y Democrático de Derecho, núm. 50, 2014, p. 49. 
amplio de la doctrina ha interpretado restrictivamente la reserva de ley orgánica que establece el art. 92.3 CE para la regulación de las modalidades de referéndum «previstas en esta Constitución». En esta lectura, la dicción del constituyente debe interpretarse «como indicativo de que solamente se cualifica como referéndum las consultas que la Constitución denomina como tal, o bien aquellas que sean reconducibles a las modalidades de referéndum expresadas en la Constitución $»^{42}$. En otras palabras, cabe hablar de referéndum sólo en relación a las consultas sobre decisiones políticas de especial trascendencia (art. 92.1 CE), la constitución de las Comunidades Autónomas previstas en el art. $151 \mathrm{CE}$, la aprobación y reforma de algunos Estatutos de Autonomía ${ }^{43}$, la reforma constitucional (arts. 167.3 y 168.3 CE) y la incorporación de Navarra al régimen autonómico vasco (Disposición adicional cuarta $\mathrm{CE}$ ), así como las específicamente establecidas en algunos Estatutos de Autonomía, esencialmente referidos a la alteración de los límites territoriales de una Comunidad Autónoma (art. 149.2.b CE) $)^{44}$. Por el contrario, tanto las consultas locales como, en su caso, las organizadas por las Comunidades Autónomas en relación a asuntos públicos de su competencia carecerían de esta naturaleza referendaria.

Pero, aunque esta doctrina ha encontrado acomodo en la jurisprudencia del TC (por ejemplo, en las SSTC 103/2008 FJ 2-3 y 31/2010 FJ 69 y, previamente, en las SSTC 76/1994 FJ 3 y 119/1995 FJ 3) ${ }^{45}$ no está exenta de contradicciones sustanciales. Una aplicación literal de esta singularidad del referéndum consistente en que toda consulta sobre un asunto público, dirigida a la generalidad de la población de un ámbito territorial específico, debe considerarse un referéndum en cuanto a los requisitos formales de su celebración, como parece desprenderse de la STC 31/2015, impondría la necesidad

42 Vid. CARrasco Duran, M., «Referéndum versus consulta», Revista de Estudios Políticos, núm. 160, abril-junio, 2013, p. 17.

${ }^{43}$ Se acogerían a este supuesto los arts. 46 y 47 del Estatuto de Autonomía del País Vasco, los arts. 222.1 y 223.1 del Estatuto de Autonomía de Cataluña, los arts. 56 y 57 del Estatuto de Autonomía de Galicia, los arts. 248 y 249 del Estatuto de Autonomía de Andalucía, el art. 81.5 del Estatuto de Autonomía de la Comunidad Valenciana y el art. 115.7 del Estatuto de Autonomía de Aragón.

${ }^{44}$ Este sería el caso del art. 8 del Estatuto de Autonomía del País Vasco y de la Disposición transitoria tercera.1.c) del Estatuto de Autonomía de Castilla y León habla de «refrendo» entre los habitantes del territorio, municipio o municipios. La constitucionalidad de estas consultas fue admitida por la STC 99/1986 (FJ 5) y reiterada posteriormente (cfr. STC 103/2008 FJ 3).

${ }^{45}$ La STC 103/2008 (FJ 2) declara que «los mecanismos de participación directa en los asuntos públicos quedan restringidos a aquellos supuestos en los que la Constitución expresamente los impone [...] o a aquellos que, también expresamente contemplados, supedita a la pertinente autorización del representante del pueblo soberano (Cortes Generales) o de una de sus cámaras»». 
de ampliar el criterio de singularización del instituto referendario o bien establecer que, simplemente, el criterio constitucional las prohíbe, especialmente en lo que respecta al ámbito autonómico. Sobre esta incongruencia, LÓPEZ BASAGUREN ha señalado que «la pretensión de que solo constituyan supuestos de referéndum los así previstos expresamente en la Constitución siendo posible el establecimiento de otros instrumentos idénticos sin esa denominación aboca a una diferenciación puramente nominal que es insostenible $»^{46}$.

También, la jurisprudencia constitucional ha tratado ampliamente la cuestión relativa a los límites del ámbito material de las consultas ex art. 91 $\mathrm{CE}$, aunque sobre este particular la doctrina del TC ha dado muestras de una notable vacilación. Así, la ratio decidendi que parecía apuntar el fundamento jurídico cuarto de la STC 103/2008 expresaba el criterio de que el límite de las decisiones políticas que pueden someterse a referéndum consultivo (art. $92 \mathrm{CE}$ ) se encuentra en cualquier cuestión que comporte iniciar un proceso de reforma constitucional, dado que la pregunta en sí ya supone una reforma de hecho de la Constitución, apuntando a una lógica en la que, como ya había advertido VIVER I PI-SUNYER,

«ni el Estado ni las comunidades pueden consultar a los ciudadanos sobre la posibilidad de iniciar procesos de reforma y, más concretamente, no pueden consultar sobre cuestiones que, en la hipótesis de que obtuviesen el voto favorable de los ciudadanos, requiriesen iniciar un proceso de reforma de la Constitución $\rangle^{47}$.

Precisamente, son diversos los autores que han remarcado la inconsistencia de este planteamiento, aduciendo el hecho de que lo distintivo del objeto del referéndum consultivo es que «lo que se somete a consulta popular es una determinada opción política al margen del proceso de creación, modificación y derogación de normas, al margen del proceso legislativo» (MARTíN NúÑEZ ${ }^{48}$. Todo ello, además, inserto en un ordenamiento constitucional del cual se ha subrayado su desvinculación del modelo de «democracia militante» y en el que, en consecuencia, tienen cabida todo tipo de concepciones que pretendan modificar el fundamento mismo del orden constitucional, incluido,

46 Vid. López Basaguren, A., «Sobre referéndum y Comunidades Autónomas. La ley vasca de la "consulta" ante el Tribunal Constitucional (consideraciones con motivo de la STC 103/2008)», Revista d'Estudis Autonòmics i Federals, núm. 9, octubre, 2009, p. 217.

47 Vid. Viver i Pi-Sunyer, C., «El reconeixement de la plurinacionalitat de l'Estat en l'ordenament jurídic espanyol», en REQUEJO, F. y GAGNON, A., (Ed.), Nacions a la recerca de reconeixement. Catalunya i el Quebec davant el seu futur, Institut d'Estudis Autonòmics, Barcelona, 2010, pp. 222-223.

${ }^{48}$ Cfr. op. cit, 2012, p. 102. 
por ejemplo, la alteración del estatus jurídico de una Comunidad Autónoma; una carencia de límites materiales en la reforma constitucional que ha sido avalada por una sólida línea jurisprudencial del $\mathrm{TC}^{49}$.

Con todo, como ya hemos argumentado, la STC 42/2014 pareció establecer una inflexión substancial en el criterio de la jurisprudencia constitucional, ya que en ella el elemento material en cuestión -el ejercicio del «derecho a decidir»-, no se limita, únicamente, a la posibilidad de impulsar un proceso de reforma constitucional. Es más, declara, de forma explícita, que los poderes públicos de una comunidad autónoma pueden legítimamente realizar actividades dirigidas a «preparar o defender» el objetivo político que estimen conveniente, sin excluir explícitamente ningún instrumento, lo cual podría entenderse como una aceptación tácita de la posibilidad de una consulta previa a la de ratificación de una reforma constitucional. En este nuevo esquema, la obligatoriedad de la reforma constitucional parece a todas luces posponerse a la fase del ejercicio efectivo del «derecho a decidir».

Es evidente, sin embargo, que un planteamiento de este registro colisiona con la concepción de determinados sectores doctrinales que se inspiran en la existencia implícita de límites a la intangibilidad de la Norma Fundamental $\mathrm{y}$, en íntima conexión con ello, sobre los límites materiales de una consulta referendaria. Así, por ejemplo FONDEVILA MARÓN ha señalado que:

«Una correcta comprensión, a nuestro juicio, del instrumento de la Reforma, obliga a comprender que toda operación de esta naturaleza está sometida a límites materiales estén o no expresados en el texto constitucional en forma de cláusulas de intangibilidad. (...) Esta cuestión hunde sus raíces, evidentemente, en algo más profundo como lo es el concepto mismo de Constitución, pues los que mantengan la existencia de tales límites serán los que manejen un concepto material de Constitución, identificando la Carta Magna con determinados principios y valores característicos de una Comunidad Política, por contraposición a aquellos que ven en la Constitución simplemente un documento normativo situado en la cúspide del sistema de fuentes $\rangle^{50}$.

La posibilidad, explorada también por parte del Parlamento catalán ${ }^{51}$, de obtener una delegación estatal, ex art. 150.2 CE, para la convocatoria de un

49 Vid. las SSTC 48/2003 (FJ 7), 103/2008 (FJ 3), 31/2010 (FJ 12) y 42/2014 (FJ 4).

${ }^{50}$ Cfr. op. cit, 2014, p. 603.

51 El 16 de enero de 2014, el Parlamento de Catalunya aprobó la Resolución 479/X en la cual se acuerda presentar a la Mesa del Congreso de los Diputados la «Proposición de ley orgánica de delegación a la Generalitat de Catalunya de la competencia para autorizar, convocar y celebrar un referéndum sobre el futuro político de Catalunya» (BOPC, X legislatura, núm. 221 de 17.12.2013). La iniciativa de delegación no realizaba ninguna precisión concreta sobre la cuestión a plantear, que se remitía a una negociación bilateral 
referéndum ha sido también objeto de controversia doctrinal por su contenido material, poniendo en duda que mediante la previsión del art. 150.2 CE pueda traspasarse cualquiera de las competencias contempladas en el art. 149.1 CE como exclusivas del Estado, pero en el caso de transferencia de la capacidad organizativa de un hipotético referéndum a través del cual pudiera ejercerse el «derecho a decidir» ${ }^{52}$.

Refiriéndose a la LORMR, el Consell de Garanties Estatutàries (CGE) en su dictamen 3/2010 aprecia que, dado el contexto histórico en el que fue elaborada, no se pretendía un desarrollo completo de esta institución de democracia directa, y menos todavía un régimen exhaustivo del ejercicio del derecho fundamental a la participación. En opinión del CGE, la LORMR regula esencialmente las diversas modalidades de referéndum previstas en la Constitución y sólo algunas de sus previsiones, contenidas en el capítulo II («Del procedimiento para la celebración del referéndum»), constituyen un desarrollo directo del artículo $23 \mathrm{CE}$, como también lo son algunas de la Ley orgánica 5/1985, del Régimen Electoral General (LOREG), a las cuales remite la misma LORMR (art. 19). De hecho, dado que el art. 81 CE no actúa propiamente como un título competencial, no excluye necesariamente la intervención autonómica, como se ejemplifica en los casos, reiteradamente citados por la doctrina, de la iniciativa legislativa popular y del régimen electoral, dos ámbitos del derecho de participación política, desarrollados mediante legislación orgánica, en los que existe una abundante legislación autonómica.

\section{CONCLUSIONES}

La reciente STC 31/2015, sobre la Ley catalana de consultas populares no referendarias y participación ciudadana, ha venido a completar un periplo interpretativo del Tribunal Constitucional sobre el instituto referendario, iniciado con la STC 103/2008, a propósito de la Ley del Parlamento Vasco sobre la consulta del llamado «Plan Ibarretxe 2», y que prosiguió

Estado-Generalitat, es decir, no excluía, por ejemplo, la posibilidad de que la cuestión planteada finalmente sea una reforma constitucional. Finalmente, presentada y discutida la proposición de ley orgánica en el Congreso de los Diputados el 8 de abril de 2014, está fue rechazada por un amplio margen (Diario de Sesiones del Congresos de los Diputados, X Legislatura, núm. 192, 8.04.2014).

52 «[R]epugna a la lógica jurídica que un mecanismo constitucional (la trasferencia de una competencia a una Comunidad Autónoma) pueda servir para destruir el principio de soberanía que la misma contiene. Nuestra tesis consiste en que ni siquiera podría el Gobierno autorizar a los órganos de la Comunidad Autónoma a su celebración» (Cfr. FonDEVILA MARON, M., «Derecho a decidir y soberanía. A propósito de la sentencia 42/2014, de 25 de marzo», op. cit., p. 598-599). 
con otras dos relevantes Sentencias como son la STC 31/2010 sobre el EAC (FJ 69) y la 42/2014, sobre la declaración de soberanía del Parlamento de Cataluña.

Podría decirse que el nexo común de todas ellas era el propósito de dar respuesta a distintos planteamientos, más o menos explícitos, del llamado «derecho a decidir», primero por parte de la Comunidad del País Vasco y, después, de Cataluña, cuya máxima instancia representativa, como es bien sabido, ha venido ejecutando, una tras otra, una panoplia de vías jurídicas con acomodo en el marco constitucional vigente, para llevar a cabo una consulta al conjunto de su ciudadanía, con todas las garantías democráticas, sobre el futuro político de su Comunidad.

Estas diferentes tentativas han concitado no sólo un amplio rechazo de las principales fuerzas políticas estatales sino también colisionado frontalmente con una jurisprudencia constitucional extraordinariamente rígida en lo que respecta a la formalización y uso de los instrumentos de democracia directa, particularmente del referéndum. Ésta se ha mostrado incluso refractaria a la posibilidad de mitigar, en su caso, los controles estatales a los que aquel está sometido, pese a que, en algún momento (muy señaladamente la STC 42/2014) pareció que dicho criterio era susceptible de cierta flexibilización.

Así las cosas, en un momento en que arrecia incluso la controversia doctrinal sobre la existencia implícita de un principio de intangibilidad en la Constitución ${ }^{53}$, puede afirmarse que parece cada día más lejano el criterio de sensatez esbozado por un importante sector doctrinal, en el sentido de hallar un cauce interpretativo, dentro del marco del derecho positivo español, favorable a una aspiración política tildada de «legítima» por el TC (y de «derecho moral» por RUBIO LLORENTE ${ }^{54}$ ), especialmente en ausencia de toda iniciativa política conducente a operar las pertinentes reformas legales. En otras palabras, a la luz al menos de la doctrina constitucional no parece vislumbrarse la posibilidad de que vaya a poderse materializar una consulta sobre una cuestión que tanto importa a un parte nada despreciable de la sociedad catalana, ni siquiera la posibilidad de que ese deseo pueda expresarse a través de sus representantes legítimos.

${ }^{53}$ Cfr. Fondevila Maron, M., «Derecho a decidir y soberanía. A propósito de la sentencia 42/2014, de 25 de marzo», op. cit.; CARRASCO DURAN, M., «Referéndum versus consulta», op. cit., 2013.

54 Rubio Llorente, F., «Principios y conveniencias», La Vanguardia, 18 de diciembre de 2013. 
TITLE: The oscillating doctrine of the Constitutional Court on the definition of the public consultations by referendum. A critical review through four judgments.

RESUMEN: Con su Sentencia 31/2015, sobre la Ley catalana de consultas populares no referendarias y participación ciudadana, el Tribunal Constitucional completa un conjunto de pronunciamientos doctrinales sobre el referéndum que comprende, principalmente, otras tres relevantes Sentencias (la 103/2008, la 31/2010 y la 42/2014). En el presente articulo se examinan críticamente estas cuatro Resoluciones que, si bien contienen aspectos que expresan una doctrina dubitativa e incluso confusa, cierran por ahora la jurisprudencia básica para la delimitación del género consultas populares, el reparto competencial en la materia y, sobre todo, los criterios para la determinación de las materias que pueden ser objeto de consulta.

PALABRAS CLAVE: Consulta popular, consulta no refendaria, jurisprudencia, Tribunal constitucional.

ABSTRACT: With its Judgment 31/2015, on the Catalan Law on popular consultations and citizen participation, the Spanish Constitutional Court completes a set of doctrinal statements on the referendum comprising mainly three more relevant judgments (the 103/2008, the $31 / 2010$ and 42/2014). This article discusses these four texts, although at times, express a hesitant and confused doctrine, they form the basic law for the definition of the genre popular consultations, the situation of regional powers in this area and finally criteria relating to restrictions on matters that can be consulted.

KEY WORDS: Consultations, consultations different to referendums, jurisprudence, Constitutional Court. 
